\title{
Sistem Pengukuran Kinerja Manajemen untuk Mengevaluasi Tujuan Perusahaan Menggunakan Model Balanced Scorecard dan Gamification
}

\author{
Management Performance Measurement System to Evaluate Company \\ Objective Using the Balanced Scorecard and Gamification Model
}

\author{
Herda Dicky Ramandita*1, Ema Utami ${ }^{2}$, Emha Taufiq Luthfi ${ }^{3}$ \\ 1,2,3 Magister Teknik Informatika Universitas Amikom Yogyakarta \\ E-mail: *1herda.ramandita@gmail.com, 2ema.u@amikom.ac.id, \\ 3emhataufiqluthfi@amikom.ac.id
}

\begin{abstract}
Abstrak
Perusahaan adalah setiap bentuk usaha yang melakukan kegiatan secara tetap dan terus-menerus dengan memperoleh keuntungan dan atau laba bersih, baik yang diselenggarakan oleh orang perorangan maupun badan usaha yang berbentuk badan hukum atau bukan badan hukum, yang didirikan dan berkedudukan dalam wilayah negara RI. Kemajuan teknologi yang terus berkembang selalu memberikan perubahan - perubahan baru dalam meningkatkan kualitas dan kinerja suatu perusahaan, dalam era perkembangan teknologi yang semakin kompetitif perusahaan dituntut mampu menyusun menajemen strategis dalam rangka mengembangkan organisasinya agar dapat bertahan dan memenangkan persaingan. Pengukuran kinerja merupakan salah satu faktor yang penting dalam mencapai tujuan perusahaan, Salah satu model pengukuran kinerja adalah Balance Scorecard. Balance Scorecard adalah pengukuran kinerja perusahaan yang modern dengan mempertimbangan empat perspektif (yang saling berhubungan) yang merupakan penerjemahan strategi dan tujuan yang diingin dicapai oleh suatu perusahaan, yang kemudian diukur dan dimonitor secara berkelanjutan. Model lain yang bisa diadopsi adalah Gamification, gamification merupakan integerasi game element kedalam sistem informasi atau aplikasi non-game. Sistem pengukuran kinerja menggunakan model Balanced Scorecard yang didukung dengan Gamification menjadikan model Balanced Scorecard lebih interaktif.
\end{abstract}

Kata Kunci — kinerja manajemen, balanced scorecard, gamifikasi

\begin{abstract}
Company is any form of business conducting activities on a regular basis and continuously, whether held by individuals or business entities which are legal entities or legal entities, established and domiciled within the territory of the Republic of Indonesia. Technological advancements are always evolving always provide new changes in improving the quality and performance of a company, in an era of increasingly competitive technological development companies are required able to arrange management in the framework of organizational development in order to survive and win. Balance Performance Scorecard is one of the important factors in achieving company goals. Balance Scorecard is a modern enterprise performance measurement with consideration of four perspectives (interconnected) which is a translation of strategy and goals desired by a company, which is then measured and monitored continuously. Another model that can be adopted is Gamification, gamification is an integeration game element in information systems or non-game applications. The Balanced Scorecard system is more interactive. The Balanced Scorecard model is more interactive.
\end{abstract}

Keywords - performance managemet, balanced scorecard, gamification 


\section{PENDAHULUAN}

Dalam menyusun manajemen strategis, perusahaan harus memiliki tujuan yang sejalan dengan visi misi perusahaan. Visi merupakan gambaran tentang masa depan yang realistik dan ingin diwujudkan dalam kurun waktu tertentu. Visi adalah pernyataan yang diucapkan atau ditulis hari ini, yang merupakan proses manajemen saat ini yang menjangkau masa yang akan datang [1] Misi adalah pernyataan mengenai hal - hal yang harus dicapai organisasi bagi pihak-pihak yang berkepentingan di masa datang [1] Pernyataan misi mencerminkan tentang penjelasan produk atau pelayanan yang ditawarkan. Selain Sumber daya alam yang tersedia keberhasilan suatu organisasi, lembaga pendidikan atau bahkan perusahaan adalah kualitas sumber daya manusia yang berada di lingkungan tersebut [2].

Pengukuran kinerja merupakan salah satu faktor yang penting dalam mencapai tujuan perusahaan. Pihak manajemen juga dapat menggunakan pengukuran kinerja perusahaan sebagai alat untuk mengevaluasi pada periode yang lalu. Belum adanya visi misi \& tujuan serta sistem kinerja yang terukur membuat PT. GIT Solution kesulitan dalam mengevaluasi kinerja perusahaan.

Salah satu model pengukuran kinerja adalah Balance Scorecard. Balance Scorecard adalah pengukuran kinerja perusahaan yang modern dengan mempertimbangan empat perspektif (yang saling berhubungan) yang merupakan penerjemahan strategi dan tujuan yang diingin dicapai oleh suatu perusahaan, yang kemudian diukur dan dimonitor secara berkelanjutan. Pengukuran kinerja tersebut memandang unit bisnis dari empat perspektif, yaitu perspektif keuangan, pelanggan, proses bisnis internal, serta proses pembelajaran dan pertumbuhan [3]. Keunggulan pendekatan BSC dalam sistem perencanaan strategis adalah mampu menghasilkan rencana strategis, yang memiliki karakter yaitu: Komprehensif, Koheren, Seimbang, dan Terukur [4].

Model lain yang bisa diadopsi adalah Gamification, Gamification memungkinkan aplikasi bisnis menyenangkan untuk digunakan. Pengguna akan diberikan imbalan ketika melakukan kegiatan di dalam sistem dan pengguna lain dapat melihat performa dari masing masing pengguna [5] Gamification merupakan integerasi penggunaan anatra game element dan teknik game design ke dalam aplikasi non-game seperti website, program pelatihan internal, kegiatan pembangunan masyarakat, pemasaran produk dan layanan pelangagan untuk mendorong perilakau yang diinginkan [6].

Sistem pengukuran kinerja yang baik akan memberikan manfaat kepada perusahaan berupa perencanaan kinerja perusahaan tercapai dan sesuai dengan target yang telah ditetapkan serta pendapatan perusahaan menjadi meningkat dan kesejahteraan karyawan menjadi lebih baik [7]. Membangun konsep IT dengan menggabungkan model Balanced Scorecard dan metode Gamification dapat mempermudah pihak manajemen melakukan pengukuran kinerja dan membantu pihak manajemen mengukur sejauh mana keberhasilan perusahaan dalam mencapai tujuan serta dengan adanya game mechanic konsep IT yang diharapkan mampu memberikan motivasi, kesenangan dan hal menarik lainnya.

\section{METODE PENELITIAN}

\subsection{Balanced Scorecard}

Balanced scorecard merupakan konsep yang mulai dikembangkan dalam strategi bisnis. Konsep ini dianggap mampu mengukur kinerja bisnis yang telah dicapai, sehingga diharapkan mampu mempercepat tercapainya tujuan bisnis yang menguntungkan. Pada tahun 1990, Robert S. Kaplan dan David P. Norton telah mempopulerkan konsep baru untuk mengukur kinerja suatu manajemen. Konsep ini diberi nama balanced scorecard. Balanced scorecard adalah suatu konsep manajemen yang menekankan pada pengukuran keuangan dan non keuangan berdasarkan visi 
dan misi suatu perusahaan. Adanya balanced scorecard, dapat digunakan sebagai alat komunikasi dalam suatu perusahaan atau bisnis.

Balanced scorecard adalah salah satu alat yang digunakan oleh manager untuk mengukur kinerja suatu bisnis yang dilihat dari empat perspektif. Keempat perspektif itu terdiri dari perspektif keuangan, perspektif pelanggan, perspektif proses bisnis internal, serta perspektif pertumbuhan dan pembelajaran. Perspektif balanced scorecard dapat dilihat pada Gambar 1.

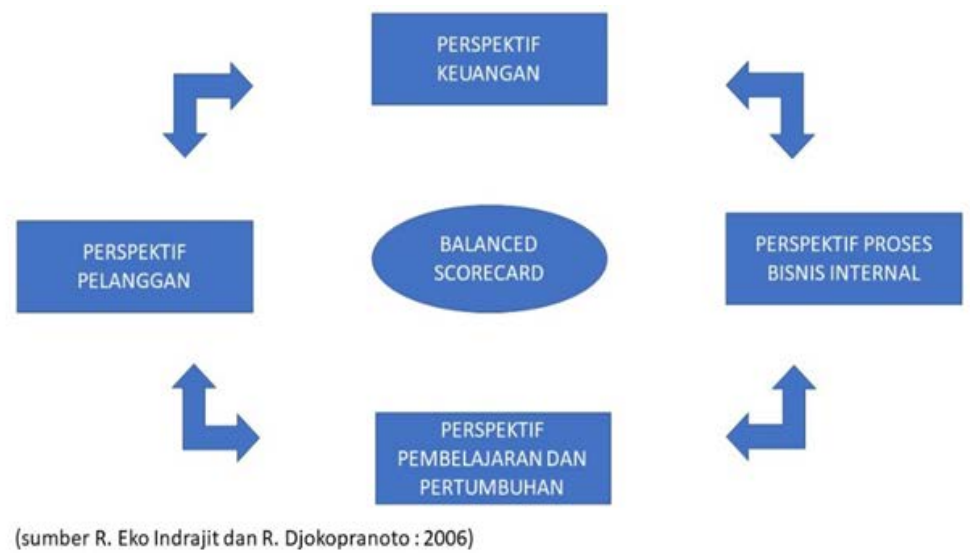

Gambar 1. Perspektif Balanced Scorecard

\subsubsection{Perspektif Keuangan}

Kinerja keuangan dapat dilihat dari jumlah penerimaan dan pengeluaran. Ada 3 tahapan bisnis, yaitu bertumbuh (growth), bertahan (sustain), dan menuai (harvest). Growth adalah tahap awal suatu bisnis. Perusahaan dituntut untuk dapat mengembangkan produknya, fasilitas dan sistem operasinya, serta menciptakan hubungan baik dengan pelanggan. Hal ini dilakukan untuk mengukur tingkat penjualan produk di pasaran.

\subsubsection{Perspektif Pelanggan}

Sebelum memasarkan produknya, perusahaan harus menentukan target pemasaran produk. Fokus utama dari suatu bisnis adalah pelanggan. Oleh sebab itu, suatu perusahaan sebaiknya mampu menghasilkan produk sesuai dengan kebutuhan pelanggan. Produk yang dihasilkan harus memiliki kualitas yang baik. Perspektif pelanggan juga dapat dinilai dari kemampuan perusahaan dalam mempertahankan hubungan baik dengan pelanggan.

\subsubsection{Perspektif Proses Bisinis Internal}

Perspektif proses bisnis internal ini dapat dilihat dari proses yang digunakan untuk mencapai peningkatan pelanggan serta untuk memberikan kepuasan kepada para pemegang saham. Tahapan dalam proses ini terdiri dari proses inovasi, operasional, dan pelayanan. Proses inovasi adalah cara perusahaan mengembangkan produknya untuk mencukupi kebutuhan pelanggan. Keberhasilan proses ini dapat dilihat dari jumlah produk yang dikembangkan, besarnya minat konsumen terhadap produk yang baru, besarnya biaya yang diperlukan, serta besarnya prosentase pengembangan (modifikasi) terhadap produk lama.

\subsubsection{Perspektif Pembelajaran dan Pertumbuhan}

Perspektif ini dilakukan untuk mendorong perusahaan agar tetap tumbuh. Hal-hal yang perlu diperhatikan dalam perspektif ini antara lain, karyawan dan sistem informasi. Tingkat kepuasan karyawan harus diperhatikan agar dapat mendorong kinerja karyawan, sehingga mampu menghasilkan ide-ide kreatif. Sistem informasi juga harus diperhatikan agar cepat dalam memperoleh informasi mengenai kondisi pasar. 


\subsection{Gamification}

Gamifikasi adalah suatu proses yang menggunakan pemikiran dan mekanika permainan untuk mengikat user dan menyelesaikan masalah [8]. Gamifikasi merupakan konsep yang menggunakan mekanika permainan, estetika, permaianan yang melibatkan antara pemikiran dan orang tindakan motivasi, mendorong kegiatan belajar serta menyelesaikan permasalahan [9].

Contoh elemen-elemen yang pada gamifikasi adalah berbasis game (game based), mekanika (game mechanic), estetika, pola piker permainan (game thinking), terikat (engagement), orang (people), tindakan motivasi (motive action), mempromosikan pembelajaran dan memcahkan masalah (problem solving) dijelaskan sebagai berikut [10].

\subsubsection{Berbasis Permainan}

Menciptakan sebuah sistem di mana peserta didik, pemain, konsumen dan karyawan terlibat dalam tantangan abstrak yang ditentukan oleh aturan, interaktivitas dan umpan balik yang menghasilkan yang terukur idealnya memunculkan reaksi emosional.

\subsubsection{Mekanika}

Level, badges, point, score dan time challenge adalah elemen yang digunakan sebagian besar permainan. Game Mechanic saja tidak cukup untuk mengubah pengalaman yang membosankan menjadi sebuah permainan, seperti pengalaman menarik, akan tetapi semuanya merupakan satu kesatuan yang utuh seperti setiap bagian dari tiap bangunan itu penting, terutama dalam proses penggunaan metode gamifikasi.

\subsubsection{Estetika}

User interface dan nuansa dari pengalama user merupakan elemen penting dalam proses penerapan metode gamifikasi. Bagaimana pengalaman estetika tersebut dirasakan oelh seseorang sangat mempengaruhi atas ketersedian user untuk menerima gamifikasi.

\subsubsection{Pola Pikir Permainan}

Ide berpikir tentang pengalaman sehari - hari seperti aktivitas jogging atau lari dan mengubah aktivitas tersebut menjadi suatu kegiatan yang memiliki unsu - unsur persaingan, kerjasama, ekplorasi dan storyline.

\subsubsection{Terikat}

Sebuah tujuan dari proses penggunaan metode gamifikasi adalah mendapatkan perhatian user dan melibatkan merekan dalam proses yang telah dirancang.

\subsubsection{Orang}

Orang tersebut dapat peserta didik, konsumen atau pemain. Mereka adalah user yang akan terlibat dalam proses menciptkan dan siapa yang akan termotivasi untuk mengambil tindakan.

\subsubsection{Tindakan Memotivasi}

Motivasi adalah proses yang memberikan energid an memberikan arah, tujuan atau makna perilaku dan tindakan. Bagi individu yang termotivasi, tantangan tidak boleh terlalu keras bahkan terlalu sederhana. 


\subsubsection{Mempromosikan Pembelajaran}

Gamifikas dapat digunakan untuk mempromosikan pembelajaran karena banyak unsur dalam metode gamifikasi didasarkan pada psikologi Pendidikan dan Teknik yang didesain oleh instruktur, guru dan dosen yang telah menggunakan sejak lama.

\subsubsection{Memecahkan Masalah}

Gamifikasi memiliki potensi yang baik untuk membantu memecahkan masalah. Sifat kooperatifdari game dapat memutuskan perhatian pada pemecahan masalah individu. Sifat kompetitif banyak mendorong untuk melakukan permainan terbaik mereka untuk mencapai tujuan untuk menang.

\subsection{Action Research}

Dalam penelitian ini menggunakan metode Action Research (AR) atau penelitian tindakan merupakan salah satu bentuk rancangan penelitian, dalam penelitian tindakan peneliti mendeskripsikan, menginterpretasikan dan menjelaskan suatu situasi sosial pada waktu yang bersamaan dengan melakukan perubahan atau intervensi dengan tujuan perbaikan atau partisipasi. Tahapan dalam penelitian ini dapat dilihat pada Gambar 2.
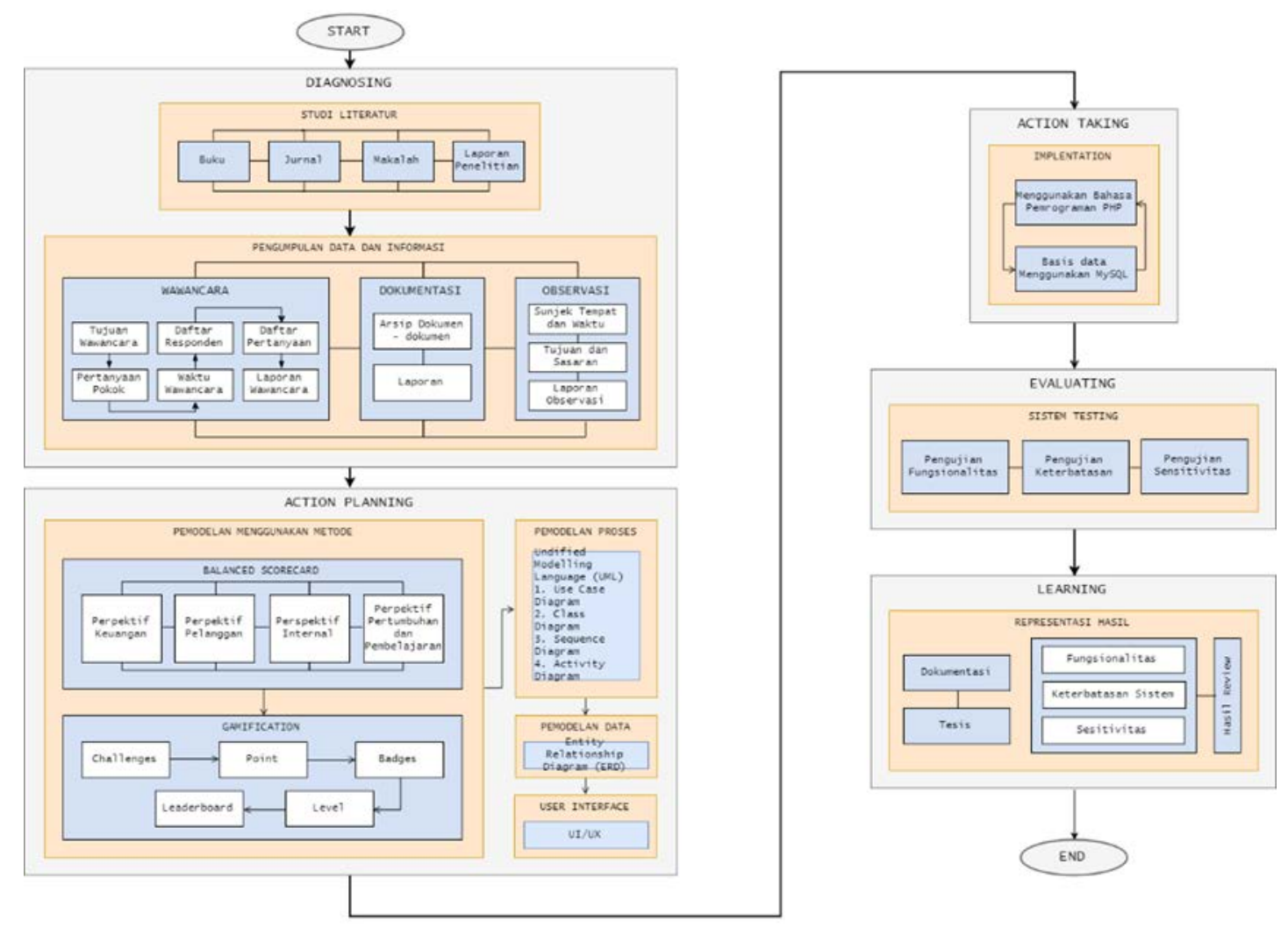

Gambar 2. Alur Penelitian

\subsubsection{Tahap Dianosa}

Pada penelitian ini metode pengumpulan data yang digunakan adalah observasi dan wawancara kepada pihak manajemen PT. GIT Solution dalam hal ini Direktur Utama, Direktur Operasional dan Manajer masing-masing divisi/departemen terkait untuk mengetahui rencana strategis PT. GIT Solution. 


\subsubsection{Tahap Rencanaan Tindakan}

Analisis data menggunakan model Balance Scorecard berdasarkan 4 (empat) perspektif, yaitu: perspektif keuangan, perspektif pelanggan, perspektif proses internal dan perspektif pembelajaran dan pertumbuhan dan model gamifikasi untuk mendukung sistem pengukuran kinerja.

\subsubsection{Tahap Tindakan}

Tindakan yang dilakukan adalah membuat rancangan sistem Job Performance Scorecard berupa pemodelan proses dengan menggunakan Undified Modeling Language (UML), pemodelan data menggunakan Entity Relation Diagram (RED) dan pembuatan User Interface atau rancangan antar muka pengguna. Selanjutnya diimplementasikan menggunakan Bahasa pemrograman PHP dan basis data MySQL.

\subsubsection{Tahap Evaluasi}

Dalam tahap evaluasi sistem pengukuran kinerja Job Performance Scorecard terdiri dari pengujian fungsionalitas sistem, pengujian keterbatasan sistem dan pengujian sensitivitas sistem untutk mengetahui apakah sistem sudah berjalan dengan baik.

\subsubsection{Tahap Pembelajaran}

Hasil review terhadap fungsionalitas sistem, pengujian keterbatasan sistem dan pengujian sensitivitas sistem merupakan bagian akhir siklus yang telah dilalui dengan melaksanakan review tahap - perhapan yang telah berakhir kemudian penelitian ini dapat berakhir.

\section{HASIL DAN PEMBAHASAN}

Perancangan konsep IT sistem pengukuran kinerja manajemen Job Performance Scorecard menggunakan 5 tahapan dalam metode Action Research sebagai berikut diantaranya tahapan diagnosa, rencana tindakan, tindakan, evaluasi, pembelajaran.

\subsection{Tahan Diagnosa}

1. Belum efektifnya evaluasi kinerja untuk perkembangan perusahaan dalam mencapai target.

2. Belum adanya dokumentasi atau pencatatan tentang perencanaan dan realisasi target yang ditentukan oleh perusahaan.

3. Belum adanya alat bantu untuk mengukur keberhasilan visi dan misi perusahaan.

\subsection{Rencana Tindakan}

Dari hasil diagnosa penelitian ini tindakan yang dilakukan adalah membuat peta stategis, yang diharapkan dapat memudahkan perusahaan dalam mengkomunikasikan target - targetnya kepada karyawan sehingga perusahaan dapat mengevaluasi rencana pencapaian yang ditargetkan. Rancangan perspektif dan sasaran strategis dijabarkan dalam Tabel 1.

Tabel 1. Rancangan perspektif dan sasaran strategis

\begin{tabular}{|l|l|l|l|}
\hline No & \multicolumn{1}{|c|}{ Perspektif } & \multicolumn{1}{|c|}{ Sasaran Strategis } & \multicolumn{1}{|c|}{ Penanggung Jawab } \\
\hline 1 & Keuangan & 1. Pendapatan yang besar & $\begin{array}{l}\text { 1. Direktur Utama } \\
\text { 2. Direktur Operasional }\end{array}$ \\
\hline 2 & Pelanggan & $\begin{array}{l}\text { 1. Pendapatan penjualan } \\
\text { 2. Hubungan pelanggan } \\
\text { 3. Promosi produk }\end{array}$ & 1. Divisi Marketing \\
\hline
\end{tabular}




\begin{tabular}{|c|c|c|c|}
\hline No & Perspektif & Sasaran Strategis & Penanggung Jawab \\
\hline 3 & Proses Internal & $\begin{array}{l}\text { 1. Pengembangan high quality product/ } \\
\text { project } \\
\text { 2. Training Service }\end{array}$ & $\begin{array}{l}\text { 1. Divisi Sofware } \\
\text { Developement } \\
\text { 2. Divisi Games }\end{array}$ \\
\hline 4 & $\begin{array}{ll}\text { Pembelajaran } & \text { dan } \\
\text { Perkembangan } & \end{array}$ & $\begin{array}{l}\text { 1. Peningkatan kemampuan programming } \\
\text { 2. Riset Pasar } \\
\text { 3. Pengembangan modul training }\end{array}$ & $\begin{array}{l}\text { 1. Divisi Sofware } \\
\text { Developement } \\
\text { 2. Divisi Games } \\
\text { 3. Divisi Marketing }\end{array}$ \\
\hline
\end{tabular}

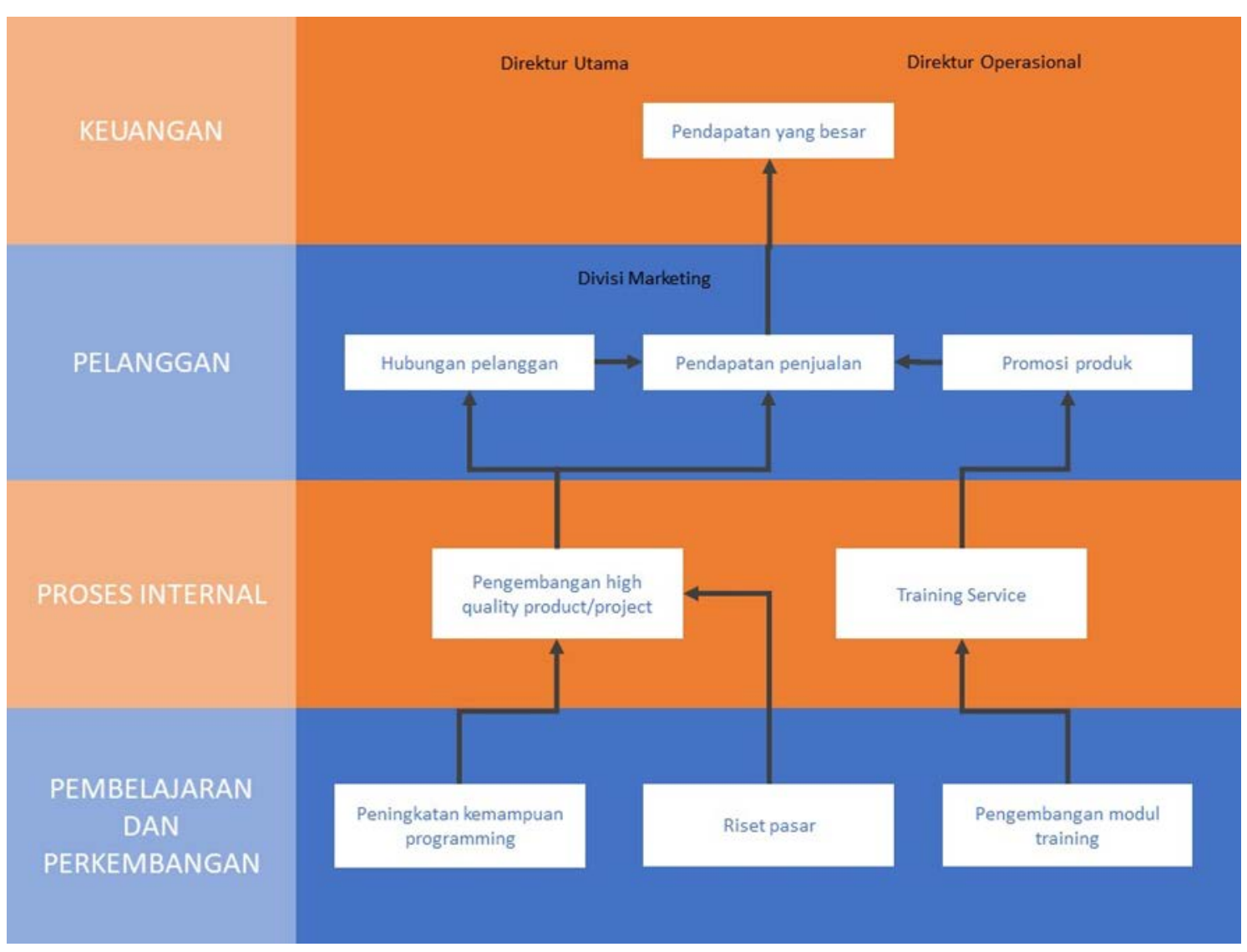

Gambar 3. Peta Strategis PT. Git Solution

Mengadopsi peta strategis pada Gambar 3, penerapan game mechanic untuk merancang sistem dengan menggunakan metode gamifikasi sebagai berikut.

1. Challanges \& Point

Tabel 2. Tabel Challenges \& Point

\begin{tabular}{|c|l|c|}
\hline No & \multicolumn{1}{|c|}{ Challanges } & Point \\
\hline 1 & Pendapatan penjualan & 10 \\
\hline 2 & Hubungan pelanggan & 20 \\
\hline 3 & Promosi produk & 5 \\
\hline 4 & Pengembangan high quality product/project & 20 \\
\hline 5 & Training Service & 10 \\
\hline 6 & Peningkatan kemampuan programming & 15 \\
\hline 7 & Riset Pasar & 10 \\
\hline 8 & Pengembangan modul training & 10 \\
\hline
\end{tabular}


Citec Journal, Vol. 4, No. 4, Agustus 2017 - Oktober 2017

\section{Badges}

Tabel 3. Tabel bedges

\begin{tabular}{|l|l|l|l|}
\hline \multicolumn{1}{|c|}{ Badges } & Gambar & \multicolumn{1}{|c|}{ Keterangan } & \multicolumn{1}{c|}{ Syarat } \\
\hline $\begin{array}{l}\text { Mission } \\
\text { Complete }\end{array}$ & & $\begin{array}{l}\text { Didapatkan ketika karyawan } \\
\text { telah menyelesaikan tugas }\end{array}$ & Semua level \\
\hline $\begin{array}{l}\text { Master } \\
\text { Schedule }\end{array}$ & & $\begin{array}{l}\text { Didapatkan ketika karyawan } \\
\text { bisa menyelesaikan tugas tepat } \\
\text { waktu }\end{array}$ & Semua level \\
\hline
\end{tabular}

\section{Leaderboards}

Menampilkan hasil pencapaian dari seluruh karyawan antara satu karyawan dengan karyawan yang lainnya dengan urutan ranking tertinggi dan terendah. Leaderboards sendiri dapat memacu kompetisi yang positif antar karyawan apabila diterapkan.

\subsection{Tindakan}

Implementasi dari konsep IT yang diterapkan pada sistem informasi pengukuran kinerja dengan model balanced scorecard dan gamification berupa pemodelan proses dengan menggunakan Undified Modeling Language (UML), pemodelan data menggunakan Entity Relation Diagram (RED) dan pembuatan User Interface atau rancangan antar muka pengguna Selanjutnya diimplementasikan menggunakan Bahasa pemrograman PHP dan basis data MySQL. Berikut adalah tampilan antar muka halaman dashboard sistem pengukuran kinerja Job Performance Scorecard pada Gambar 4.

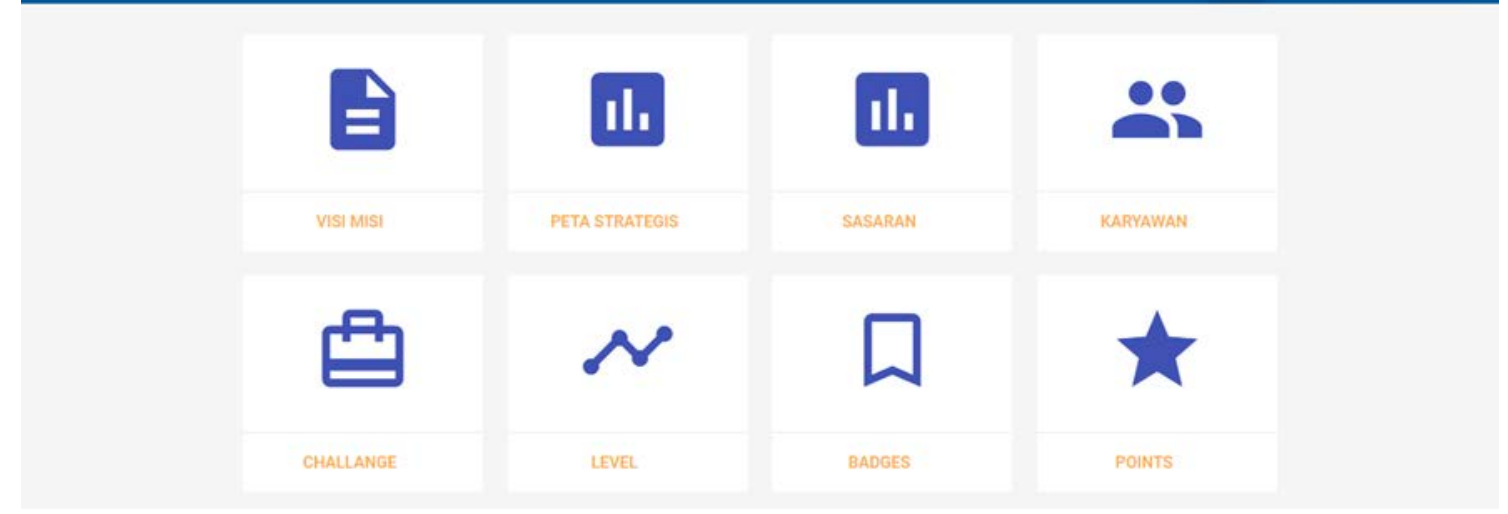

Gambar 4. Halaman antarmuka sistem informasi Jop Performance Scorecard

\subsection{Evaluasi}

Evaluasi sistem pengukuran kinerja Job Performance Scorecard terdiri dari pengujian fungsionalitas sistem, pengujian keterbatasan sistem dan pengujian sensitivitas sistem untutk mengetahui apakah sistem sudah berjalan dengan baik. 


\subsection{Pembelajaran}

Tahapan pembelajaran merupakan bagian akhir dari siklus yang telah dilalui dengan melaksanakan review tahap - pertahap yang meliputi:

1. Review rancangan peta strategi.

2. Review sasaran strategis dari setiap perspektif Balance Scorecard.

3. Review penerapan game mechanic pada sistem pengukuran kinerja Job Performance Scorecard.

4. Review hasil pengujian aplikasi

\section{KESIMPULAN}

Dari hasil penelitian yang dilakukan dengan judul "Sistem Pengukuran Kinerja Manajemen Untuk Mengevaluasi Tujuan Perusahaan Menggunakan Model Balanced Scorecard Dan Gamification”, ditarik kesimpulan sebagai berikut.

1. Pengukuran kinerja sebagai alat bantu evaluasi perusahaan dalam menilai pencapaian tujuan yang telah ditargetkan belum dimiliki oleh PT. GIT Solution. Sehingga keberhasilan yang telah dicapai kurang dimanfaatkan sebagai tolak ukur dalam menentukan target di periode selanjutnya.

2. Model pengukuran kinerja yang digunakan pada penelitian ini adalah model Balance Scorecard yang didukung oleh Gamification. Balance Scorecard adalah pengukuran kinerja perusahaan yang modern dengan mempertimbangan empat perspektif yang berhubungan. Empat perspekstif ini diterjemahan dalam strategi dan tujuan yang ingin dicapai oleh perusahaan, yang kemudian diukur dan dimonitor secara berkelanjutan. Sedangkan, Gamification memungkinkan aplikasi bisnis lebih menyenangkan untuk digunakan. Gamification mengintegerasikan game element dengan teknik game design ke dalam aplikasi non-game.

3. Hasil evaluasi dan perencanaan menggunakan model Balance Scorecard yang terdiri dari 4 (empat) perspektif yaitu perspektif keuangan, perspektif pelanggan, perspektif proses bisnis internal, perspektif pertumbuhandan pembelajaran, menghasilkan 9 (sembilan) sasaran strategis.

\section{SARAN}

Berikut ini beberapa saran yang kami rumuskan bgai peneliti selanjutnya agar dapat ditanggapi atau dapat dilakukan tindak lanjut dari hasil penelitian ini:

1. Perlu dibuat Key Performance Indicator yang lebih beragam.

2. Jenis/kategori bedges bisa lebih bervariasi agar implementasi gamifikasi lebih menarik.

\section{DAFTAR PUSTAKA}

[1] Akdon, 2009, Manajemen Strategik untuk Manajemen Pendidikan, Alfabeta, Bandung.

[2] Sundari, S. S., Pramana, H. J., 2016, Perancangan Sistem Informasi Penilaian Kinerja Instruktur dengan Metode Analytical Hierarchy Prosess, Citec Journal, Vol. 3, No. 2, Hal $126-134$.

[3] Yowono, S., 2006, Petunjuk Praktis Penyusunan Balanced Scorecard, PT. Gramedia Pustaka Utama, Jakarta.

[4] Mulyadi, 2001, Balanced Scorecard Alat Manajemen Kontenporer untuk Pelipatganda Kinerja Keuangan Perusahaan, Salemba Empat, Jakarta. 
Citec Journal, Vol. 4, No. 4, Agustus 2017 - Oktober 2017

[5] Risal, 2013, Pembangunan Gamification (Game Mechanics) Framework, ITB, Bandung.

[6] Huotari, K., Hamari, J., 2012, Defining gamification: a service marketing perspective, MindTrek '12 Proceeding of the 16th International Academic Mind Trek Conference, (hal.17-22). Tampere, Finland, 3-5 Oktober 2012.

[7] Riza, B. S., 2015, Pengukuran Kinerja Perusahaan Menggunakan Analytic Network Process (Studi Kasus di PT. Telemedia Network Cakrawala), Eksplora Informatika. Vol. 5, No. 1, Hal $51-62$.

[8] Zichermann, G., Cunningham, C., 2011, Gamification by Design, O’Reilly Media. Inc, Sebastopol.

[9] Kapp, K. M., 2012, The Gamification of Learning and Instruction: Game-based Methods and Strategies for Training and Education, Pfieffer, San Francisco.

[10] Kapp, K. M., Cone. J., 2012, What Every Chief Learning Officer Needs to Know about Games and Gamification for Learning. Department of Instructional Technology and Institute for Interactive Technologies. 